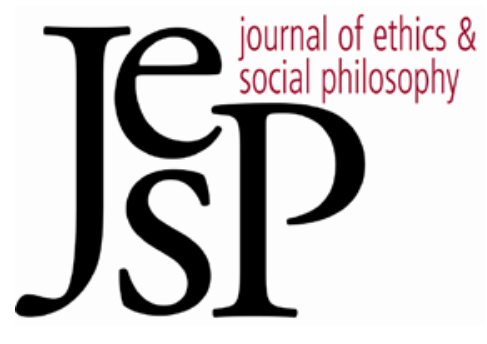

\title{
Distributing Collective Obligation
}

By SEAn Aas

JOURNAL OF ETHICS \&SOCIAL PHILOSOPHY

Vol. 9, NO. 3 | OCTOBER 2015

URL: WWW.JESP.ORG

COPYRIGHT @ SEAN AAS 2015 


\section{Distributing Collective Obligation \\ Sean Aas}

\section{$\mathrm{I}$} 1939, GERMANY INVADED CZECHOSLOVAKIA. Several major powers denounced the invasion. But the (mostly moribund) League of Nations proved ineffectual at coordinating intervention, and the (severely weakened) Czechoslovakian state was unable to mount real resistance. In retrospect, it seems clear that the other great powers of the time should have intervened before matters came to this point - and that, since they did not, they were partly responsible for the horrors that followed. Of course, it never should have come to that: The German people should never have allowed the Nazi party to take power in the first place, and once it became clear how they would act when in power, the German army should have overthrown them.

Groups like these act. Sometimes they are obligated to act. And sometimes they are responsible or culpable for not acting, when they are obligated to act and do not. Group action and group responsibility have received a fair amount of philosophical attention. ${ }^{1}$ Group obligation has, until recently, received much less. But this is changing. ${ }^{2}$ It is becoming clear that some important moral-philosophical issues turn on questions concerning which groups can be obligated to act. The contemporary global justice literature, for instance, asks whether there is any agent on which obligations of global justice might fall. ${ }^{3}$ Some argue, e.g., that, though strong principles of egalitarian justice like Rawls's difference principle apply within state-governed societies taken singly, they do not apply across state borders, because no transnational agent has an obligation to see them fulfilled. 4

This sort of issue cannot be settled without a clearer conception of collective agency and obligation than we currently have. ${ }^{5}$ Much of the existing literature on this begins with questions about the conditions under

\footnotetext{
1 Indeed there are quite large literatures on both questions; for background and bibliographies cf. A. S. Roth (2011) "Shared Agency," Stanford Encyclopedia of Philosophy, spring 2011 edition, E. N. Zalta, ed., plato.stanford.edu/archives/spr2011/entries/shared-agency. M. Smiley (2011) "Collective Responsibility," Stanford Encyclopedia of Philosophy, fall 2011 edition, E. N. Zalta, ed., plato.stanford.edu/archives/fall2011/entries/collective-responsibility. ${ }^{2}$ Cf. e.g., B. Wringe (2014) "Collective Obligations: Their Existence, Their Explanatory Power, and Their Supervenience on the Obligations of Individuals," European Journal of Philosophy.

${ }^{3}$ For some discussion, see B. Wringe (2005) "Needs, Rights, and Collective Obligations," Royal Institute of Philosophy Supplements 80(57): 187-208; B. Wringe (2010) "Global Obligations and the Agency Objection," Ratio 23(2): 217-31; A. Schwenkenbecher (2013) "Joint Duties and Global Moral Obligations," Ratio 26(3): 310-28.

${ }^{4}$ S. Freeman (2007) "Distributive Justice and the Law of Peoples," in Justice and the Social Contract, Oxford: Oxford University Press, pp. 297-321.

5 Unlike many authors, I normally use "group" and "collective" interchangeably here, to refer to any arbitrary set of agents. This usage is meant to leave open, at the outset, all questions concerning which sets of individuals can act or be obligated as collective agents.
} 
which collectives constitute an agent, asking for various putative obligations whether there are existing organized "agents" capable of fulfilling them. I take a different approach here, starting with the question of collective obligation, and proceeding only then to questions about collective agency. My strategy is to begin by developing an account of member obligation: What must be true of the members of a group if that group is to have an obligation? The thought, then, is that this account can be used as a heuristic for discovering potentially obligated collectives. If it is true of each of some collection of individuals, $I$, that they have the individual obligations they would have if they constituted a collective agent, $C$, that was obligated to do some thing, $\phi$, then it should be plausible that they do in fact constitute an obligated collective, and therefore plausible that they are, in at least a minimal sense, an agent.

My approach, then, is to begin by arguing for some necessary conditions for collective obligation, and then use these to propose an account of prospectively sufficient conditions for a collective to be obligated to act.

I argue, first, that, to know when a collective obligation entails obligations on that collective's members, we have to know, not just what it would take for each member to do their part in satisfying the collective obligation, but also what they should do if they cannot do their part because others will not do theirs. I go on to argue (contra recent proposals) that it is not good enough for members in this situation to reasonably believe that others will not do their part. Rather, for a member of an obligated collective to permissibly escape doing her part in a collective obligation, she must both reasonably doubt that others will do theirs and stand ready to act in case others become ready as well.

This condition concerning member obligation, I argue, is necessary for collective obligation. But it is not yet sufficient: A collective, all of whose members are obligated to be ready to act together, might still not be obligated to act if coordination problems make it impossible to translate individual readiness into collective action. However: (a) If a collective's members are obligated to be ready to do their part, in a given collective action, and (b) if that readiness makes it sufficiently likely that the collective will in fact act, then, I argue, there should be no bar to an attribution of collective obligation. In particular, in that case, I argue, there ought to be no additional objection that there is no existing, organized, "agent" on which the obligation might fall: The only organization required for collective obligation is the organization required for some collection of individuals to act as a result of widespread individual readiness to act if others will act.

I go on to argue that these are relatively narrow grounds for rejecting putative collective obligations - narrow enough that we should be open to the possibility that many such obligations apply to many relatively unstructured groups, including, probably: the German army, the prewar powers and perhaps even the people of the world at large.

${ }^{6}$ H. Lawford-Smith (2012) “The Feasibility of Collectives' Actions," Australasian Journal of Philosophy 90(3): 453-67. 


\section{Member Obligation: Some Existing Accounts}

Member obligations, again, are the obligations that individual constituents or members of an obligated collective have when and in virtue of the fact that this collective has this obligation. A very simple sort of account of this might say, only: When a collective is obligated to do something, all of its members are obligated to do their part in that thing. Suppose that, for our tow-truck company to tow a car, the owner has to provide a functioning truck and impound lot, the dispatcher has to take the call, and the driver has to hitch the car and pull it to the impound lot. On this simple account, the company's obligation to tow entails an obligation on each of us to do this thing - the owner is obligated to provide the truck, the dispatcher to take the call, and the driver to hitch and deliver. However, in some cases, some members of an obligated collective will know that there is no point in doing their part, since others will certainly not do theirs. In those cases, it is not plausible to say that they are obligated to do their part anyway - the driver need not and should not hitch up the car if the owner has not provided a lot to tow it to. ${ }^{7}$

A slightly more complicated account tries to avoid "pointless" member obligations like these. On this account, the members of an obligated collective are obligated, only, to do their parts in the collectively obligated action, provided others are doing theirs. But this account will not work either. As Robert Goodin points out, making member obligations merely a matter of doing a part if others do threatens to allow badly motivated members of collectives to "let each other off the hook" far too easily, solely because they are all so badly motivated that none can be expected to do their part.8 Suppose that nobody in our tow-truck company cares about their job. So nobody is doing their part to tow the cars we have agreed to tow. But nobody cares enough to even check whether others would do their part if they did theirs. On the present proposal, these suppositions entail that nobody in our group ought to do anything about our collective obligations. This, however, is ridiculous - we cannot let each other off the hook so easily, by being so badly motivated. We must therefore still have some member obligations, in respect of a collective obligation, even when others are not doing their part.

\footnotetext{
7 Bill Wringe seems to disagree, asserting that: "If, in a particular situation a collective C has an all-out obligation to Phi, then, for any member $\mathrm{M}$ of $\mathrm{C}$, and for any set $\mathrm{S}$ of possible actions of members of $C$ that, if performed together, would constitute C's Phi-ing, if S includes M's doing A, then M has a pro tanto obligation to do A." I do not see why we should posit even a pro tanto obligation in cases in which attempts to fulfill it would be fruitless. The reasons must be theoretical; we have to posit these implausible obligations to explain other, more plausible claims about member obligation. I refute these reasons, in effect, by offering an alternative theory, which does not posit pointless individual obligations, even pro tanto. B. Wringe (2014) "From Global Collective Obligations to Institutional Obligations," Midwest Studies in Philosopby 38(1): 171-86.

8 Cf. R. E. Goodin (2012) "Excused by the Unwillingness of Others?” Analysis 72(1): 1824.
} 
So, there is some obligation that applies to each of us when we are a member of an obligated collective, even if we know that other members of this collective will not do their parts. This obligation, however, need not attach to an action aimed at promoting the performance of the collective obligation: Sometimes, perhaps, there is nothing we can or can be asked to do that will make collective performance any more likely. Even in those cases, however, utter indifference to collective obligation seems wrong. That is, it seems that, when we are a member of an obligated group, we ought to: do our part, or to in some sense care, to form some yetto-be-specified attitude, about doing our part. This attitude, whatever it is, "lets us off the hook" for a collective action when we cannot do our part because others will not do theirs. So, to determine which memberobligations follow from a collective obligation, we should ask: What attitudes must we have if we are to be "off the hook" - immune to blame and other relevant reactive attitudes - for not doing our part in satisfying a collective obligation? Answer in hand, we could say: What we are obligated to do when we are a member of an obligated collective is to act if we can, or, if we cannot, have this attitude instead.

Holly Lawford-Smith proposes one such answer; since my different answer will arise from problems with hers, I will discuss her account in some detail here. ${ }^{10}$ Lawford-Smith proceeds from the natural thought that, sometimes, the members of an obligated collective are not obligated to do their part in trying to fulfill that collective obligation because they reasonably believe that it would be futile to do so - since, so they reasonably believe, others will not do their part in turn. On this account, a collective is obligated to do something only if its members are obligated to: do their part in that thing unless they reasonably believe that (enough) others will not do theirs (so as to prevent the collective from satisfying the obligation). ${ }^{11}$

This account has the right logical structure to solve the aforementioned problem concerning the distribution of collective obligation. ${ }^{12}$ Critically, as Lawford-Smith emphasizes, the member obligation it identifies takes wide scope over a conditional connecting an action and an attitude. It does not say, merely: If we reasonably believe others are not going to do their part, then we are not obligated to do ours. That narrow-scope version would not say what obligation we in fact still have when we are not obligated to do our part in a collective action; thus, it would not explain

\footnotetext{
9 By "immune" to blame I mean blameless in the distinctive (and here unexplained) way that those who have lived up to their obligations are blameless; as opposed, e.g., to the distinctive (also here unexplained) way in which those who have valid excuses for failing to perform obligations are blameless.

10 Op. cit.

${ }^{11}$ Lawford-Smith's account, like my later revision of it, posits "obligations" that attach to things that are not "actions," strictly speaking - for her, beliefs, for me, beliefs and intentions. Neither Lawford-Smith nor I mean to take controversial stances on (e.g.) doxastic voluntarism by talking this way. Per n. 9, the only thing that matters here is whether individuals can be held to account for their beliefs and mental states; it seems clear that they can - that they ought to have some and ought not to have others.

12 Ibid.: 459, 462-63.
} 
what goes wrong when we "let each other off the hook" by futilityinducing indifference. The wide-scope version, by contrast, posits a conditional - or, equivalently, disjunctive - obligation, which remains in force whether or not both its disjuncts are satisfied: Whether or not we believe others are going to do their part, we remain obligated to: do our part, or to reasonably believe that it would be futile to do so, because others will not do theirs. There is thus a sense in which we must "care" about a collective obligation even if we cannot perform our part in it; we must then have certain beliefs about it.

Promising as this is, however, I argue that it is both too strong and too weak to capture member obligation. It requires too much of the beliefstates of members of obligated collectives, and too little of their motivations.

To start to see this, notice that, sometimes, groups do seem to be obligated even though none of their members have Lawford-Smith's belief-concerning obligation.

Consider, for instance, the Roman Emperor Caligula's bodyguard. Let us suppose that Caligula was as bad as they say he was; also, that only his bodyguard could remove him, and only by assassinating him. And suppose that, due to surveillance, etc., the guards were unable to conspire with one another to plan the assassination (which, let us also say, no one of them can do alone). Since a failed attempt would result in horrible consequences for the would-be assassins, and success is not in any case certain, no one guard can be reasonably confident that others will join an attempt he begins. Still, all the guards see the horrible things Caligula does, and know that decent, honorable Romans, like their fellow guards, will be revolted by them, and may be willing to take steps to remove him if others will take similar steps. So they cannot be reasonably confident, either, that others will not do their part, if they take the first step. Given the horrible consequences of starting an assassination attempt that others do not take up, it is not plausible that any one guard is obligated to start, given this condition of uncertainty. No one of Caligula's guards, then, is obligated to begin an assassination attempt, even though none can reasonably believe that the others will not help if they do begin. Still, the bodyguard as a collective does seem to have an obligation to assassinate the emperor - after all, it is tremendously important that it get done, they are uniquely well positioned to do it and, if they try together to do it they will do it, and indeed do it without too much risk or trouble.

This suggests, contra Lawford-Smith, that there are cases in which a collective is obligated to do something, though no member is obligated to either do their part or reasonably believe that (enough) others will fail to do theirs. Now, this might seem to be at best a minor quibble with Lawford-Smith's proposal. Does it not show at most, then, that the beliefstate needed to escape a collective obligation is rational confidence that others will not act, rather than a lack of rational confidence that they will?

This, I stress, is not insignificant in itself for our more general concerns. Consider the claim that the people of the developed world are obligated to end global poverty. It may be that, as it turns out, we as individuals cannot do our part in this putative obligation because enough 
others will not do theirs so that our attempts would be futile. But it may be very difficult for us to form the reasonable belief that others will not do their part, given how large and diffuse groups like this are. Thus, we as individuals may, also, be unable to satisfy Lawford-Smith's stronger belief-concerning condition. This might seem to generate an argument against the claim that the global rich have this obligation to the global poor: Since the rich as individuals cannot perform either disjunct of the disjunctive member obligation we would have, if we had this collective obligation, it may seem that we do not have this individual obligation, and therefore do not have the collective obligation. Relaxing the doxastic condition, from the presence of belief that others will not do their part to the absence of belief that they will not, removes this sort of objection, allowing collective obligations in cases in which we do not know whether other members of the collective will act if we will.

That said, a small modification of the Caligula case shows that this weaker doxastic condition does not capture everything we have to do to be "off the hook" if we cannot do our part in a collective obligation. In this version, each guard still believes, just as reasonably, that he and his fellows are good and honorable Romans, and that, if a sufficiently likely opportunity presented itself, each would be willing to participate in the assassination. But in this variant each member of the guard is (not unreasonably) mistaken about this. Sufficiently many of the others are not as decent as they seem, and will falter if an attempt begins. Those who are genuinely ready to act, plausibly, are off the hook: They have satisfied all their individual obligations in relation to this collective obligation. Those who are not ready, however, are not off the hook: They are violating their obligations here, even though they are reasonably uncertain that they can do their part. The problem is that they are not ready and willing to do their part, should they become sufficiently certain that others will as well.

Taken together, these cases show that satisfaction of member obligation does not supervene solely on actions and beliefs. Thus, collective obligations distribute not just obligations to act, or to have or lack certain beliefs, but rather obligations to act, or to have or lack certain beliefs and to have certain dispositions that will be triggered if the belief-state changes - to be ready or prepared to act if others will act, too. ${ }^{13}$ We should, therefore, make the following substantial revision of Lawford-Smith's account of member obligation:

\footnotetext{
${ }^{13}$ This may, per Goodin, op. cit., have to be short for a more complex state of mutual willingness; not "I will if you will," but rather "I will if you will and I will (if you will if I will)" (else, as Goodin argues, it not be capable of producing collective action even when all are willing). I will not come close to saying all there is to say about this sort of state, and, in particular, will not attempt to say whether and to what extent it resembles any of the various states discussed in the extensive existing literature on collective intentionality. I also leave open the significant issue of whether "preparedness" is always entirely a matter of having certain conditional intentions; for all I say here, it may be possible to satisfy member obligation by having a sufficiently good character, whether one forms the relevant intentions or not.
} 
Whenever a collective is obligated to $\phi$, its members are thereby obligated to: [ [do their part in $\phi$-ing], or [be (sufficiently, reasonably) uncertain that others will act and be prepared to [act if they become (sufficiently, reasonably) certain that others will act]]].14

(Where whether one is sufficiently reasonably certain depends on the context and, particularly, on what one knows or should know about what will happen if one attempts to act and others do not join in, and where "being prepared to $\mathrm{X}$ if $\mathrm{Y}$ " denotes a relation between a condition $\mathrm{Y}$ and an action $\mathrm{X}$, not an operation over the conditional "if $\mathrm{Y}$ then $\mathrm{X}$. ")

This is a logically complex obligation (going forward, I will refer to it as such: "the Complex Obligation"), each of whose parts requires further explanation. In the next section, I try to provide that. My approach will be to show how this complex disjunctive obligation boils down to the following much simpler claim, corresponding to the second conjunct of the second disjunct of the complex claim:

Whenever a collective is obligated to $\phi$, its members are thereby obligated to: [be prepared to: [do their part in $\phi$-ing, if they become (sufficiently, reasonably) certain that others will as well]].

The content of this claim, "the Simple Obligation," is just the last clause of the complex obligation. More specifically, the Complex Obligation has the form:

O [[PART], or [UNCERTAIN and PREP ( UNCERTAIN, PART)]]

while the Simple Obligation is:

O [PREP ( UNCERTAIN, PART)]

It is, of course, not generally true that obligations with this logical relation to one another are equivalent - an obligation to do one thing, or else two other things, does not entail an obligation to do either of the two things. In this case, however, I claim that the Complex and Simple obligations are substantially equivalent. By this I mean: (a) there are no cases in which we are prepared to do our part in a collective obligation if others do theirs, yet violate our member obligation by failing to actually do so; and (b) there are no important cases in which we do our part in a collective obligation though we violate our obligation to be prepared to do our parts if others do theirs. I will argue that (a) is so because violating an obligation to be prepared to do something under a condition entails not doing it, under that condition. And (b) holds, basically, because any cases in which members do their part without concern for whether others are doing theirs are

14 This obligation is hard to state without scope ambiguities. The admittedly unwieldy bracketing in these "official" formulations is meant to show how those should be resolved: "obligated to" takes wide scope over the whole disjunction; in the second disjunct, "prepared to" takes wide scope over the conditional. 
not good candidates for intentional collective action. The next section explains these points in more detail.

\section{Ready to Act}

In this section I argue that the Simple Obligation is, in a certain sense, primary - in the process clarifying this central notion of being "prepared" or "ready" to act.

In particular, I argue, so long as I do not violate the Simple Obligation, to be prepared to do my part in a collective obligation if I am sufficiently sure others will, I do not violate the Complex Obligation. The converse is not strictly true - I might sometimes satisfy the first clause of the Complex Obligation without satisfying the last clause - but not in any case that constitutes a challenge to my proposed expansion of the range of collectives that can have obligations.

So suppose, first, that I am a member of a collective that is obligated to perform some collective action. I have argued that this means that I am obligated to do my part, or be both sufficiently uncertain that others will do their part if I do, and prepared to do my part should I become sufficiently certain that they will do theirs. Suppose that I do not satisfy this Complex Obligation. So, both disjuncts of this disjunctive obligation fail. So, I do not do my part. Suppose now, for reductio, that I still satisfy the Simple Obligation, so that I am in fact prepared to do my part, if I become sufficiently sure that others will do theirs. I must in that case be sufficiently sure that others will do their part (since otherwise I would, per impossible, satisfy the Complex Obligation). So, I am prepared to $\phi$ under some condition $C, C$ obtains, and yet I do not $\phi$.

On one potential usage of "prepared to $\phi$ under $C$," this is impossible. To be prepared to $\phi$ under $C$, on this usage, is to be such that you will $\phi$, if $C$. This is the usage on which we might reasonably say: If I am prepared to fire if you give the order, then, at the moment you give the order, I will fire. If on being given the order I do not fire, this shows that I was not in this sense prepared to fire at the moment the order was given. Perhaps I was prepared before, and would have been prepared after, but, just then, I was not prepared.

This usage, however, is not relevant for present purposes, since whether one can be "prepared" to do something in this sense is often entirely beyond one's control. It is hard to see how we can be obligated to be prepared to do something in this strong, ability-independent sense. E.g., if my gun will jam, then I cannot fire if ordered, and therefore cannot be such that I will fire if ordered. If I am not able to ensure that the gun does not jam, then it looks like I am not able to satisfy the obligation to be prepared to fire, in the strong sense of "prepared." So, on standard assumptions, I do not have this obligation after all. 15

15 Note that, if these assumptions are false, and "ought" does not imply "can," then the point being pursued in the text follows without the ensuing complications. 
But: there still seems to be a sense in which I ought to be prepared to fire if ordered - namely, I ought to be such that, if on being ordered, I am able to fire, I will fire. Suppose, then, that I am prepared to $\phi$ under $C$ in the weaker, ability-dependent sense (that I will $\phi$ in $C$, if I can), and I do not $\phi$, despite $C$. This is not impossible. But it means that I am not able to $\phi$ under $C$. And so, it looks like I cannot be obligated to: $\phi$ under $C$ or be prepared to $\phi$ under $C$. For what could be the point of an obligation to stand ready to do something in a circumstance that I cannot do in that circumstance? 16

Thus, I conclude (filling in $\phi$ s and $C s$ ), so long as I am prepared to do my part in a collective action, if others will do theirs, I can be confident that I do not violate my obligation to - act, or, if I do not act, to not act only because, though I was prepared to act if others acted, I was sufficiently unsure that they would. Satisfying this simpler obligation is, therefore, sufficient for satisfying the more complex obligation that - so I have argued - tells me what to do when I am a member of an obligated collective.

The converse, however, is not strictly the case. I can in principle satisfy the Complex Obligation, as I have stated it, just by satisfying its first disjunct: by doing my part, whether or not I was prepared to do so under this or that condition. Doing something under a given condition does not strictly require being in a state that disposes you to do it, under that condition. E.g., I might have been utterly unprepared to fire when ordered but, by sheer luck, I might still have fired after being ordered. Similarly, there may seem to be circumstances in which members of a collective could all do their parts serendipitously (as a result, say, of a pattern of individual actions no part of which is aimed at producing the collective action in question), even if that collective lacks the structures necessary to allow its members to coordinate their individual dispositions into a coherent, "intentional," collective action.

However, if a collection of persons really were quite so unstructured, in a given interaction, then it is hard to see how this interaction could constitute a collective action subject to collective evaluation. All going theories of collective action require that intentional collective actions be produced by the interlocking intentions and beliefs of their members. ${ }^{17}$ And if a putatively obligatory collective action cannot be intentional, it is hard to see why we should posit an obligation falling on a collective, as an agent, rather than a pattern of individual obligations falling on a collective's members. So a collection of persons cannot plausibly count as each doing their part in a potentially obligatory collective action if they are not such that they can be disposed to do their parts, if others will do theirs.

It might be objected here that there are levels of member organization sufficient to generate intentional collective action but that fall short

16 Again, this does not presuppose "ought implies can" as a general thesis; its assumptions concern only the conditions under which I can be obligated to be "prepared" to do this or that under thus and so a condition.

${ }_{17}$ Cf. e.g., Roth, op. cit. 
of the sort of organization that obtains when all have the interlocking intentions required to satisfy the Simple Obligation. To be sure, so the objection goes, some willingness to act if others act seems a prerequisite for participating in intentional collective action. But the willingness in question might be more local than the Simple Obligation requires. I might, for instance, facilitate an intentional collective action out of a willingness to do only one small part of that larger action. Suppose that I, the tow-truck driver, on strike, am not willing to help tow your car, but all I need do, to see the car towed, now, is to hand the keys over to a substitute. If merely handing you the keys is doing my part, and if I hand you the keys to avoid being fired or arrested, I do my part in this collective action and therefore satisfy the Complex Obligation, without satisfying the simple one.

I want to allow, therefore, that there may be cases in which members of a group satisfy the first clause of the Complex Obligation, but not the second clause (that is, not the Simple Obligation). I stress, however, that such cases can only expand the scope of potentially obligated collective agents rather than restrict it. And that is in any case my larger purpose here. So, though there remains a question about the genuine equivalence of the Simple and Complex obligations, the answer to it should not affect any of the substantive normative claims I defend here.

I conclude that, for present purposes at least, it will make sense to treat the Simple and Complex obligations as if they were equivalent. This is fortunate, for it allows me to present my proposal much more simply: When a group is obligated to do something, its members are obligated to be prepared to do their part in that thing if (they ought to be sufficiently confident that) ${ }^{18}$ others will do theirs as well.

\section{Obligations of Unstructured Collectives}

So we have a proposed solution to the obligation-distribution problem - the problem of what follows, for the members of a collective, when that collective is obligated to act as a collective. Now, we are interested in this problem because we are interested in saying which sorts of collectives can have which sorts of obligations. To say this, though, we need more than a merely necessary condition for collective obligation. Eventually, we would want a sufficient condition as well. I have not tried to provide this yet. So far, I hope to have offered some argument for an account of the logically strongest necessary condition for collective obligation that concerns member obligation. This can lead to a sufficient condition, if - as I argue below - there are few or no necessary conditions for collective obligation that do not concern member obligations.

Before we can show that, however, we should ask: Are there any obligations that members of an obligated collective have, in virtue of their

18 I omit this epistemic qualification below as (a) verbally unwieldy, (b) plausibly implicit anyway in the non-epistemic formulation and (c) all the cases discussed abstract from it one way or another. 
membership, that do not follow from their obligation to be prepared to do their part if others do?

One reason to suspect this is so comes from the sorts of unstructured groups that are the loci of controversy in political philosophy. Some groups are such that, even if all of their members are willing to do their part in a given collective action if others will do theirs, that action still will not happen, because not enough members will become aware that others have the relevant dispositions. We might think that, in such a group, there is something more that members ought to do to see a collective obligation satisfied than, simply, to be prepared to act if others are - something to do with creating the structures necessary to convert individual dispositions to act into collective action.

Take, for instance, Lawford-Smith's treatment of the German army's putative obligation to assassinate Hitler. ${ }^{19}$ Unlike Caligula's bodyguard, the Wehrmacht would have had to coordinate in some pretty sophisticated ways to bring off an assassination (Hitler was often surrounded by guards not under Wehrmacht command). In particular, participants in a plot would have a much harder time becoming sufficiently confident that others would follow through once the plan was set in motion. Indeed, Lawford-Smith says, given the general atmosphere of mistrust that prevailed, too few Wehrmacht officers were able to signal their willingness to participate in an assassination plot to give any good chance that such a plot would come off. Lawford-Smith says that this shows that the Wehrmacht itself was not able and therefore not obligated to assassinate Hitler.

Whether she is right depends, I submit, on what the Wehrmacht officers were capable of doing to undermine or circumvent the prevailing paranoid atmosphere. For suppose that the silencing effect of this atmosphere arose in part from its interaction with pre-Nazi norms of honor and duty prevailing in the Germany army officer corps - norms that prohibited, say, certain types of deception necessary to circumvent the secret police. Suppose, then, that there was something that specific officers could have done to increase their ability to communicate - say, giving up outdated conceptions of martial honor and becoming much more willing to lie. If we conclude that each was in fact able to do this, then it starts to look less tempting to conclude that the Wehrmacht was not able to assassinate Hitler - in fact they could have done so, as follows: (1) each become willing to do so if others are similarly willing, (2) each acts to remove barriers to signaling that willingness, (3) each signals, (4) each does his part, so they together act. The group might still not be obligated if the members could not be asked to do any of (1-4) - say, because it would have been too dangerous, given the likelihood of success, or because it is wrong to lie even for such an obviously good cause. But if this was not the case, then it looks like the group could have and should have acted.

This case suggests that, along with an obligation to be willing to do their part if others will do theirs, a group obligation entails an obligation on each of its members to take steps to see that their willingness to act

19 Op. cit. 
translates into collective action. This, I think, should be granted. However, the suggestion that this latter obligation adds something morally substantial to the original (Simple) obligation I have already defended here should be resisted. Instead, we should understand all of this signaling and organizing as part and parcel of the action that members of an obligated group are obligated to be ready to undertake in the first place.

To see this, note that, in general, if I am obligated to be willing to $\phi$ if $C$, and $\psi$-ing is the only available way of $\phi$-ing, if $C$, then I am obligated to be willing to $\psi$ if $C$. For instance, if I am obligated to give you money if you serve me a meal in your restaurant, and (as I knew before ordering) you only accept cash in payment for meals, then I am obligated to be willing to give you cash if you serve me a meal in your restaurant. Similarly, if we suppose that the individual members of the German army are obligated to be willing to assassinate Hitler if others are, and that the only available way to assassinate Hitler, even if others are willing to, is to change officer corps culture, then members of the German army are obligated to take steps to change the culture. More generally: Where (a) members of a group are obligated to be willing to do their part in satisfying a collective obligation, if others will do theirs, and (b) the only available way for each of them to do this is to contribute another collective action - namely changing the way they are organized - then they are obligated to be willing to do their part in this other action, if others will do theirs in it, too.

The obligation under (a), therefore - the obligation discussed and defended here - really does, plausibly, capture the entire connection between collective obligation and member obligation. It is reasonable to suppose, then, that further member obligations obtain, if they obtain, only if (and because) this obligation obtains. ${ }^{20}$

\section{Agency and Obligation}

So, I have argued, when a collective is obligated to do something, its members are each obligated to: be prepared to do their part in that thing, should they become sufficiently certain that others will as well. This condition concerning member obligation is necessary for collective obligation. But it is not yet sufficient. For the required mutual willingness does not, in all circumstances, make collective action a real possibility, and surely (so all my opponents will agree) collective obligation cannot exist where collective action is not possible. This might have been the case, e.g., for the German army's imagined assassination of Hitler. Each officer should have been willing to go after Hitler if the others would go along, too. I argued above that if the obstacles to communicating this willingness were not insuperable, then the officers were obligated to overcome them. But, as Lawford-Smith supposes, they might in fact have been insuperable. If so, then, it looks as if the German army could not have assassinated

${ }^{20}$ I have, of course, only argued that this is so for one class of putative member obligation putatively over and above the obligation to do one's part. A more full argument to this effect would have to consider others, as well. 
Hitler. And this, we might think, entails that they were not obligated to do so.

In this section, I consider what we must add to the Simple Obligation to derive conditions sufficient for collective obligation. My claim will be that, though some additional conditions are required, they are quite minimal - not much more is required for a group to constitute an obligated collective than is required for its members to be obligated to be prepared to do their part in some collective enterprise if others will do their part as well. To show this, I will argue, following Virginia Held, that unorganized collections of strangers can constitute obligated collective agents. ${ }^{21}$ Expanding on Held, I offer an account of some conditions under which even unstructured groups can be obligated: I will maintain that if some set of individuals $I_{1} \ldots I_{n}$ are each obligated to be prepared to do their part in some collective action, were they to become sufficiently sure that others will do their part as well, and this mutual willingness is reasonably likely to lead to that action, then the group itself is obligated to act. Thus, so long as there is a way for the members of that collective to translate conditional intentions to act into collective action, they can be collectively obligated. And this can be true of, even, a collection of complete strangers.

To see this, take a case from Stephanie Collins. Suppose a bunch of beachgoers can rescue a drowning swimmer only by forming a human chain. ${ }^{22}$ Collins rightly says, about this case, that since there is a way for the beachgoers to accomplish this goal, they, as individuals, are obligated to work to do so. But Collins would say that, since the only way for them to accomplish this goal is to act together, and they do not yet constitute a collective agent, the first thing each of the beachgoers is obligated to do is to promote the existence of such a collective, by devising procedures to coordinate individual actions into a collectively effective pattern. Only after this "collectivization duty" has been satisfied is there a subject for the collective obligation to save the swimmer; beforehand, there are only individuals obligated to try to help save the swimmer by trying to collectivize as others do.

I propose, instead, that the obligation to save the swimmer falls on the beachgoers as a group as soon as they are each obligated to be willing to do so, if others will do the same. ${ }^{23}$ Given the importance of saving drowning swimmers, and supposing a low degree of risk involved in the available ways of doing so, each acquires this obligation as soon as it is true that there is a way for her to use this intention to make it significantly more likely that the swimmer will be saved. And that is true as soon as

${ }^{21}$ Held offers powerful intuitive motivation for this view in her classic (1970) "Can a Random Collection of Individuals Be Morally Responsible?" The Journal of Philosophy 67(14): 471-81.

22 S. Collins (2013) "Collectives' Duties and Collectivization Duties," Australasian Journal of Philosophy 91(2): 231-48.

${ }_{23}$ Collins does not offer an account of who counts as a "beachgoer" for the sake of this argument; nor will I - except to say that, on my account, this will be a substantive normative matter, determined by whose willingness to help might actually make some difference to whether help will be forthcoming. 
organizing to save the swimmer is possible; so, at that point the obligation to be willing to help save the swimmer if others will help entails an obligation to be willing to help organize if others will help organize, too.

It seems to me that there are strong prima facie reasons to favor my simpler account of obligation here over Collins' more complex one. To see them, suppose that the beachgoers turn out to be unconscionably lazy: None do anything to save the swimmer and the swimmer drowns, though saving her would have been relatively easy if they had tried. Something, clearly, goes very wrong here. But what? Who acts wrongly, and how? Collins will say: Each of the individuals acts wrongly, by failing to try to collectivize. But per hypothesis, all the beachgoers are lazy, thus no one of them could expect to accomplish anything at all by trying to get the others to collectivize. How, then, could it be obligatory? I, on the other hand, say that what goes wrong is that the collective fails to act on its obligation to save the swimmer - where that just means, the members fail to follow through on the consequences of their manifest obligation to be willing to save the swimmer were others to be willing, too.

It seems hard, then, to resist the claim that the swimmers are obligated, collectively, to save the swimmer, even if they do not take any steps to "collectivize." Collins, however, identifies what might seem to be a strong reason to do so: Collective obligation, she says, presupposes prior, organized, collective agency. Since the beachgoers lack this, prior to collectivizing, they cannot act collectively and therefore cannot be collectively obligated. The key point, she says, is that "only agents can bear duties," where this claim is in turn "based on the natural thought that only agents can act." ${ }_{24}$ Anne Schwenkenbecher, at one time anyway, agreed, asserting that the "'agency principle,' according to which only agents can hold duties" and a corresponding conception of collective agency on which it relies require standing organization. ${ }^{25}$

Surely Collins and Schwenkenbecher are right that "only agents can act." "Agent," after all, just means "thing that can act." Collins and Schwenkenbecher suggest that we should use this principle to reason from "is not an agent" to "cannot act," deploying independent accounts of collective intentionality to decide which collectives are agents. Notice, however, that this "agency principle" equally licenses the converse inference - from "can act" to "is an agent." Thus we could just as well start with the question, "Which collectives can act?" as with the question, "Which collectives are agents?"

\footnotetext{
24 Ibid.: 231

25 Op. cit:: 318. Schwenkenbecher does allow for "joint ability" in unstructured cases, on grounds that some unstructured groups have the ability to act together. I agree with this later claim, and offer support for it, by showing what the ability to act can come to when an unstructured group is to do the acting. I part with Schwenkenbecher on the "agency" of unstructured collectives, not on their "abilities" or "obligation"; I argue that, once we see that unstructured collectives can act, it is a very short step to the conclusion that they are agents. A. Schwenkenbecher (2014) "Joint Moral Duties," Midwest Studies in Philosophy 38(1): 58-74.
} 
This is, ultimately, a question about collective abilities. To answer it we should ask: Under what conditions does a collective of individuals have the ability to act? This is not an easy question to answer, definitively, not least because there is no single, universally accepted conception of ability to act. Many theorists of ability would agree, though, that to have an ability is to have a certain modal or dispositional property: To be able to $\phi$ is to be such that one would (or would be likely, or would be disposed to) $\phi$ if one tried to $\phi \cdot{ }^{26}$ So if we wanted to know what duties collectives can have, we can begin by asking: What does it take for it to be true of a collective that it would (be likely to/be disposed to) act, if it tried to act?

There is, I believe, good reason to think that uncoordinated groups can "try" to do things, and can sometimes succeed as a result of this trying. To see this, suppose that our beachgoers each individually form an intention to save the drowning swimmer if others will. There is no trying yet. Suppose, however, that they start talking to each other, frantically looking for a way. This time, however, they do not find one in time, and the swimmer drowns. It seems right to say: they tried, to work together, to save the swimmer. Now, in this case, they may not have had the ability to save him. But if everything were just the same, but they succeeded, as a result of their efforts, then clearly they would have the ability to save the swimmer: They would have tried to do so, and, for that reason, succeeded. They would have had the capacity to succeed by trying, viz., to act; therefore, in that case, they would be an agent.

It might be objected here that the linguistic evidence is ambiguous: Perhaps in cases like this it is not the group itself that "tries"; rather, when we say "They tried to save the swimmer" we mean "They each tried to save the swimmer." But this is implausible. For each beachgoer knows that she cannot save the swimmer: She is too far out, and the current is too strong. Thus it would be quixotic for any one beachgoer to try to save the swimmer. To be sure, each of the swimmers can certainly, reasonably, try to help save the swimmer. But trying to help do something is not trying to do that thing - when I try to help you win the race by encouraging you to train, I am not thereby trying to win the race. Thus to capture this distributed individual trying directly, we would say, not "They tried," but, rather, "They tried to help." The trying that "They tried" identifies must therefore be the trying of something else on the beach, something that has some chance of succeeding. And here the only candidate seems to be: the beachgoers, as an (unstructured) group.

This argument, is, admittedly, only presumptive: It remains possible that when we say "They tried" in the swimmer case we are mistaken either because we mean "They each tried" and are confused in the way just considered, or because we mean "They tried together" but are confused about the degree of organization required for a collective to try. But

${ }^{26}$ Cf. J. Maier (2014) “Abilities," Stanford Encyclopedia of Philosophy, spring 2014 edition, E. N. Zalta, ed., plato.stanford.edu/archives/spr2014/entries/abilities. As Maier discusses, this family of analyses of ability has engendered objections. Still, many theorists agree it or something like it captures something important to ability. 
this sort of error theory should not be the default view in cases like these: We need some reason to think that our initial reaction is confused here. Now, if the collective "trying" in question were utterly metaphysically mysterious, we might have such a reason: In that case the only thing we reasonably could mean by "They tried to save the swimmer" is "They each tried to," and that would be false. But we should now be in a position to see that the collective trying need not to be mysterious. For it can be, simply, a matter of each individual member of the collective satisfying their obligation to be prepared to act if others act.

Opponents of unstructured collective agency, therefore, owe us some argument that collective "trying" always comes to something more than an interlocking structure of intentions to act if others will act. Though I cannot show this detail here, it seems to me that they will not find any convincing arguments against unstructured collective "trying" in the existing literature on collective agency and intentionality. The specter of "metaphysical individualism," or skepticism about collective intentionality, presses in favor of sophistication here. The game has been to establish some plausible conditions under which individualist scruples can be assuaged and collective intentionality safely attributed. For this reason, this literature seems to be largely concerned with providing sufficient conditions for collective agency, rather than necessary conditions. ${ }^{27}$ Claims about substantial necessary conditions tend to be impressionistic - so, e.g., List and Pettit say that a group agent:

... has representational states, motivational states, and a capacity to process them and to act on that basis ... Thus the group is organized so as to seek the realization of certain motivations in the world and to do so on the basis of certain representations about what the world is like. ${ }^{28}$

This talk of "Organization" may seem problematic for my claims about unstructured agency. This, however, is not at all clear, on reflection. At most, List and Pettit show that a group agent must be as organized as it needs to be to attribute representational and motivational states to it, at the moment of action. But they do not propose any substantive standard concerning what degree of group organization is required to have mental states. ${ }^{29}$ Thus, they do not offer any argument that any more is required

${ }^{27}$ Cf., e.g., M. E. Bratman (2014) Shared Agency: A Planning Theory of Acting Together, Oxford: Oxford University Press, p. $103 \mathrm{ff}$.

28 C. List and P. Pettit (2011) Group Agency: The Possibility, Design, and Status of Corporate

Agents, Oxford: Oxford University Press, p. 32.

${ }^{29}$ List and Pettit do suggest that, to count as a "group" agent, an agent must be identifiable over time, and that unstructured agents tend to fail this test, since there is no clear criterion concerning which individual mental states combine to constitute collective cognitions and conations. They admit, however, that such groups could be what they call "joint" agents - a collective capable of acting at least once, if not repeatedly, over time $(32, \mathrm{n} .18)$. That is all that I require; my claim is only that unstructured collectives can act, and, therefore, are agents, and, therefore, can have obligations. Put another way: What matters to me is status as an "agent," not status as a standing "group." There may be further requirements on "grouphood"; there may even be further requirements on "group" agency or "corporate" agency, if organized groups have features that impose 
for a collective to act than is required for it to "try" to act. That is to say, for all they argue, it may be that when (say) each member of a group of beachgoers sees a drowning swimmer and intends to help save him if others will, then, solely in virtue of those facts, this collective counts as "wanting" to save the swimmer and "believing" that working together is the way to do so. This may or may not really be so, in the end; but if it is not so, they have not given us any reason to think it is not so.

I conclude that, even if existing accounts of collective agency and intentionality do not ratify the possibility of unstructured collective agency, they do not do much to challenge it, either.

\section{Determining Obligation}

So, I propose that, when we go to evaluate a claim of collective obligation, we should start by looking not for a collective with a rich set of mental states but, rather, only for collectives that can have the states that they must have in order to be capable of fulfilling that obligation. And, I suggest, the best way we know to do this is to see whether the members of putatively obligated collectives can act, individually, on a joint willingness to do their part in fulfilling that obligation. If they can, we should conclude that the collective in question can act, and thus that it is at the very least the right sort of thing to bear the obligation in question. Thus I think the account of member obligation proffered in the first half of the paper can help us make substantial progress on questions concerning the nature and extent of collective agency.

Notice that this sort of reasoning does not involve inferring, dubiously, directly from a putative collective obligation to the existence of a collective agent capable of fulfilling that obligation. It differs, in this respect, from the strategy proposed by Wringe: “... it is not that certain entities are morally obligated in virtue of the fact that they are agents; rather we should take them to be agents in virtue of the fact they are the subjects of moral obligation." ${ }^{30}$ Permitting this sort of reasoning, from putative obligation directly to agency, threatens to undermine an important tool for evaluating proposed collective obligations. We ought to be able to object to such a proposal on grounds that no collection of agents constitutes a collective that is able to satisfy the obligation. My approach allows this. Though it also begins with a putative collective obligation, and reasons to the existence of an agent capable of fulfilling it, along the way it inserts several further steps: First, see what member obligations that obligation would entail, and then see whether the reasons that generate the collective obligation suffice to generate the corresponding obligations concerning member intentions, considering all the while what

necessary conditions on their "trying" to do things that are not necessary conditions for disorganized groups to do so (for some related proposals, cf. K. M. Hess (2014) "Because They Can: The Basis for the Moral Obligations of (Certain) Collectives," Midwest Studies in Philosophy 38(1): 203-21). I thank an anonymous reviewer for pressing me to clarify this point.

30 Wringe 2010: 221. 
members can do and can reasonably be asked to do, and how that can and cannot add up to collective trying, and the consequent collective doing. ${ }^{31}$

This sort of reasoning in defense of a given collective obligation might fail in three basic ways. These, I now propose, constitute the only legitimate ways to resist a claim of collective obligation. Suppose, first, that the waters surrounding the drowning swimmer are infested by sharks. In that case, perhaps, nobody is obligated to be prepared to help save the swimmer even if others are willing and able to try to do so. Or suppose, second, that not enough of the beachgoers can swim. In that case, no one is obligated to be ready to jump into the water even if others are willing to do so. Even, however, if all members of a group can swim and can be asked to be willing to swim out if others will swim out, it may yet be that the group cannot act and so cannot be asked to act. This might be the case, e.g., if (third) the beachgoers share no common language and therefore cannot engage in the sophisticated coordination required to save the swimmer. In that case, we might blame them as individuals if they did not care enough about the swimmer to be ready to help if others are, but have no one to blame if they were ready but still did not help because their mutual readiness was insufficient to produce action.

Suppose, however, that a putative collective obligation passes these three tests: All the members of a group can (and can be asked to) be prepared to do their part in some collective enterprise. Suppose also that, if they all do what they can be asked to do, they will have some significant chance of succeeding in their common enterprise. In that case, it seems hard to see why we could resist the claim that the collective is obligated. Generally, when we want to resist the claim that some agent is obligated to do something, we do so either on substantive normative grounds that the agent does not have sufficient reason to do that thing, in light of his other reasons, or on the ability-based ground that the agent cannot do or (more controversially) cannot try to do the thing in question. But these grounds do not seem to apply here. Certainly there are no normative grounds to deny that the collective is obligated - for what reasons could the collective have not to act that are not also forceful reasons for the members not to be prepared to do their part in acting? Collectives lack the normative independence this would require. And for reasons already discussed, ability-based grounds do not apply here, either. For, if each of a group's members can be obligated to be prepared to act, then, if all satisfy that obligation, the group plausibly counts, thereby, as trying to act. If that is

\footnotetext{
31 Tracy Isaacs also refers to "putative" obligation in her analysis of the obligations of unstructured groups. But she uses the term differently. On her account, unorganized collectives are never actually agents, and so never actually have obligations. Rather, they have "putative" obligations in the sense of proto or quasi obligations. I argue, by contrast, (and in support of Held op. cit.) that unorganized collectives can be actual, fully real agents and have actual, fully real obligations. T. L. Isaacs (2011) Moral Responsibility in Collective Contexts, Oxford: Oxford University Press, pp. 130-55.
} 
enough to make it at least somewhat likely that the group can act, then it looks very plausible that the group in question has the ability to act.

Thus, in addition to the necessary condition for collective obligation developed above, we can propose the following necessary and sufficient condition:

A collective is obligated to $\phi$ if and only if (a) its members are obligated to: be prepared to do their part in $\phi$-ing, if they become sufficiently certain that enough others will as well and (b) if the members live up to this obligation, then (it is sufficiently likely that) the collective will $\phi$.

This is as yet only a conjecture: We would need to know more about what it takes for a collective to act by trying to act to know whether the analysis of collective ability this presupposes is adequate as such. Still, this conjecture should now be plausible enough that we should be loath to accept any objection to collective obligation that does not fit into one or the other of the categories discussed above. That is to say, we ought to be able to evaluate a claim of collective obligation by asking three questions:

The Member Ability Question: Are (enough) members of the putatively obligated collective capable of forming the sorts of intentions they would need to form to be ready to act together with the others?

The Member Normative Question: In light of their other reasons and obligations, do (enough of) the members have sufficient reason to form and maintain the relevant intentions?

The Collective Ability Question: If (enough of) the members of the collective form these intentions, is the group therefore likely (enough) to act?32

If the answer to all of these questions is "yes," for a given claim of collective obligation, then it is hard to see what reason we could have to resist that claim.

\section{Conclusions}

In light of this, what can we say about the cases with which we began? The German army's putative obligation to overthrow Hitler has already been discussed. In cases like these, in which it is difficult for members of a collective to communicate their intentions, the Collective Ability Question looms large, though the Member Normative Question also matters, since, so I argued, obligations to be prepared to do our parts in collective actions entail obligations to prepare the ground for collective action, and these may be very demanding in some contexts. Whether the German people were obligated to prevent Hitler's rise seems to turn mostly on the Collective Ability Question - Weimar institutions may

32 For an especially subtle discussion of issues relevant to this question, cf. F. Pinkert, "What We Together Can (Be Required to) Do," Midwest Studies in Philosophy 38(1): 187202. 
have made it very difficult for Germans to coordinate effective resistance early in the rise of National Socialism. The Member Ability Question, by contrast, seems to have an easier answer here - it was plainly not so hard to want Hitler gone, and to be ready to act on this desire if others would. ${ }^{33}$ This sort of question may be more relevant when we turn to questions concerning the obligations that the powers of the day had to put a stop to German aggression. Surely it is, at least, worth considering the hypothesis that, due to internal political pathologies, many of these collective agents lacked the ability to do their part in larger collective enterprises. If so, then the powers were not obligated to act together against Hitler; their inaction could still be very bad, but it would be a mistake to say it was wrong.

Turning to contemporary controversies in political philosophy, consider an aforementioned argument for denying that global scope to principles of distributive justice. Take, e.g., Rawls's difference principle. This requires, of collectives constituting social structures, that these structures be constituted so as to make the worst off within them as well off as possible. The difference principle cannot apply globally, so some would like to say, because principles of justice entail obligations and there is no global agent on which obligations of distributive justice can fall..$^{34}$ This, we are now in a position to argue, would have to be for one (or more) of three reasons.

It might be, first, because there is no collection of individuals who are able to intend to institute a global difference principle if others will try to do so as well. This seems unlikely. It might be so for a principle that required things individuals simply cannot do - live completely for the sake of others, for instance. ${ }^{35}$ But the difference principle only requires us to make the worst off as well off as we can make them; if there is not much we can do for the worst off, then the difference principle simply does not require much of us. Alternatively, it might be that, though we could implement the difference principle, we cannot want or be willing to do so, if others are willing to - because, say, it is so demanding of us that we could not sincerely want to follow it while remaining us. Some principle may be like this - say, Platonic principles requiring social structures inconsistent with the existence of families. ${ }^{36}$ But this seems hyperbolic when applied to the difference principle - hard as it is for some of us to be willing to

\footnotetext{
33 In other cases, imaginable or real, this may be much more difficult. If, e.g., a totalitarian regime succeeds in making it impossible for its subjects to conceive political life in its absence.

${ }^{34}$ E.g., S. Freeman (2007: 316): "So a global difference principle would be without both agency and object - no legal person to implement it, and no legal system to which it is applicable."

35 Assuming, plausibly (and again independently from "ought implies can"), that we cannot be obligated to intend to do something under a condition that we cannot do under that condition.

${ }^{36}$ For discussion cf. D. Estlund (2011) "Human Nature and the Limits (if Any) of Political Philosophy," Philosophy \& Public Affairs 39(3): 211f.
} 
make ourselves poorer than we are, even were others to do so as well, surely it is not so hard as to be impossible.

So a second sort of reason to doubt the existence of a subject for a global difference principle may be more forceful: It may be that not enough individuals globally have sufficient reason to be prepared to act, if others act as well. To know whether a global difference principle is in this sense over-demanding, we would have to settle questions that go far beyond the scope of this discussion. Still, some of what we have learned here can help us to see how to go about discussing these questions. We should be convinced by now that whether we are obligated to be willing to do our part in a collective action does not depend directly on how likely it is that others will or will not be to do theirs. This, I have argued would make it too easy for us to let each other off the hook by way of mutual unwillingness. On the other side, we should not take conditional intentions to be, as it were, too cheap. For whether I have moral reason to intend to do something under a condition surely depends in some significant way on whether I would have sufficiently strong reason to do that under that condition. ${ }^{37}$

Finally, third, it might in principle be the case that, though there are collections of individual agents who are obligated to be prepared to institute a global difference principle if others are, none of these collections is such that if they all do what follows from this obligation, they together will implement a global difference principle. In that case, it would be natural to say that there is no global group able to implement the difference principle. To see how we might begin to evaluate this claim, note first that it does not follow from the fact that no group is currently sufficiently well organized to implement a global principle. Rather, per the above, it would have to be that no extant collection of individuals could become capable of doing this. ${ }^{38}$ This is far from obvious. But it is also far from obviously false - serious arguments can and have been offered. Perhaps, for instance, as Friedrich von Hayek argued, there are insuperable informational problems for any attempt to impose a distributive principle in a complex system. ${ }^{39}$ Or perhaps any agency with the knowledge and power to implement such a principle globally would be too dangerous in other ways, as, for instance, a traditional (Kantian) line of argument holds con-

\footnotetext{
37 The qualifier "enough" raises a thorny question here. Recall, per above, that this just means "enough so that if each does his part the action will be completed." But how easy it is for me to do my part in a collective action, when enough others are doing theirs, may turn on how much more than enough others are doing or are likely to do. Should facts about this sort of probability affect my obligations, or is this another way for us to illegitimately "let each other off the hook"? I am not sure.

${ }^{38}$ For discussion of duties to increase capacity for collective action, cf. P. Gilabert (2009) "The Feasibility of Basic Socioeconomic Human Rights: A Conceptual Exploration," The Philosophical Quarterly 59(237): 559-81.

39 This is, as Hayek intended, not just a reason to resist a global difference principle but, also, to resist any difference principle at all. F. A. Hayek (1973) Law, Legislation and Liberty, Vol. 1: Rules and Order, Chicago: University of Chicago Press.
} 
cerning a global state. 40 Evaluating these complex counterfactual hypotheses would go well beyond the scope of my discussion here. I hope only to have shown what some ways of resolving them would imply concerning potential obligations of global distributive justice.

So, I have argued: A collective is obligated to do something only if the members of that collective are obligated to be willing to do their part in that thing. More tentatively, I have offered some reason to think that, if a set of agents is obligated to be willing to do their part in some collective action, and is such that, if they each satisfy this obligation, they will act together, then they are obligated to act together. This approach, I suggested, allows us to recognize obligations of highly unstructured collectives: What matters is not present organization, but rather capacity to achieve enough organization to act in the case in question. That said, it does not leave us without any resources to deny claims of collective obligation on grounds that members lack corresponding obligations. To the contrary, this framework directs us to a series of questions concerning the members of an allegedly obligated collective, answers to which might or might not substantiate that allegation. These questions are not easy to answer. Still, having them to ask makes it at least a little easier to see how we should proceed in adjudicating claims about collective obligation. Answering these questions in the affirmative - concluding, say, that a difference principle could apply globally - will not tell us everything we might want to know about member obligation. It will not tell us, for instance, who should be ready to do what, to see a global difference principle satisfied. But it does tell us that we should want to know this; that this principle does apply to the people of the world taken as a collective; and thus that each person has some obligation to look for ways to work with others to see it satisfied. 41

Sean Aas

National Institutes of Health

Department of Bioethics

sean.aas@gmail.com

\footnotetext{
40 I. Kant (1983) Perpetual Peace, and Other Essays on Politics, History, and Morals, T. Humphrey, trans., Indianapolis: Hackett Pub. Co.

${ }^{41}$ Needless to say, the views discussed here do not represent the position of the National Institutes of Health or the U.S. government. Substantial portions of this work were completed during a fellowship at the Center for Advanced Studies Justitia Amplificata. I thank the Center for its generous support. This paper benefitted from discussions with Derek Bowman, David Estlund, Tim Syme and the members of the Web of Belief discussion list. Thanks also to Sarah Goff, Alan Wertheimer, Bill Wringe and several anonymous reviewers for discussion and comments on drafts.
} 